\title{
ФИСКАЛЬНЫЙ ИНСТРУМЕНТ УПРАВЛЕНИЯ РАЗВИТИЕМ СЕКТОРА МАЛОГО И СРЕДНЕГО ПРЕДПРИНИМАТЕЛЬСТВА
}

\author{
(c) 2020 Родионов Дмитрий Григорьевич \\ доктор экономических наук, профессор, Высшая инженерно-экономическая школа \\ Санкт-Петербургский политехнический университет Петра Великого (СПбПУ), \\ Россия, Санкт-Петербург \\ E-mail: dmitry.rodionov@spbstu.ru \\ (c) 2020 Ялымов Сергей Вячеславович \\ Высшая инженерно-экономическая школа \\ Санкт-Петербургский политехнический университет Петра Великого (СПбПУ), \\ Россия, Санкт-Петербург \\ (c) 2020 Сергеев Дмитрий Анатольевич \\ кандидат экономических наук, доцент, Высшая инженерно-экономическая школа \\ Санкт-Петербургский политехнический университет Петра Великого (СПбПУ), \\ Россия, Санкт-Петербург \\ E-mail: sergeev_da@spbstu.ru
}

Сектор малого и среднего предпринимательства является системообразующем для отечественной экономики. При этом, подавляюще большинство инструментов институциональной поддержки бизнеса ориентированы на крупный бизнес, вследствие чего малый и средней бизнес должны коррелировать свои интересы с крупным бизнесом. В рамках данной статьи предлагается институциональный инструмент управления развитием сектора малого и среднего предпринимательства, носящий фискальный характер и основанный на принципе опционного контракта. Гибкий характер предлагаемого инструмента позволит динамически трансформировать характеристики фискальной поддержки представителей малого и среднего бизнеса.

Ключевые слова: опцион, малый и средние бизнес, МСП, налоговые льготы, фискальные инструменты, модель Блэка-Шоулза, Биномиальная модель, цена опциона.

Одним из наиболее значимых институциональных инструментов управления развитием являются налоги, сборы и иные инструменты фискального типа. Данный факт обусловлен следующим:

1. Налоговое бремя в Российской Федерации для бизнеса достаточно значимое и дифференцированное. Общее налоговое бремя в экономике России (как сумма всех налоговых платежей и социальных взносов по отношению к ВВП) составляет 31,6\% на март 2020 года. За последние 10 лет налоговая нагрузка на экономику России как росла, так и сокращалась. Так, в 2007 году она составляла 36,5\% ВВП, на пике кризиса в 2009-м - 30,9\%, после чего вновь выросла - до $34,4 \%$ в 2014 году [1]. При этом, наиболее значимой данная нагрузка является в части налогов на оплату труда. Так как ни один субъект МСП не может существовать без трудовых ресурсов, данный инструмент воздействия является край- не актуальным.

2. Государство обладает фискальной монополией. Именно государство определяет состав налогов и сборов, а также ставки и периодичность уплаты. Таким образом, данный инструмент находимся в абсолютном управлении государством, что в свою очередь снижает вариативность результатов и трудоемкость принятия решений.

Необходимость своевременной уплаты налоговых платежей является конституционной обязанностью всех гражданина и предприятий Российской Федерации. Полная или частичная неуплата (или несвоевременная уплата) налогов и сборов компенсируется государству полным погашением задолженности, а также возмещением ущерба, который государство понесло в связи с фактом недополучения планового налогового дохода. В связи с этим к сумме задолженности добавляется дополнительная денеж- 
ная сумма - пени, которая направлена именно на компенсацию потерь государства. Принято считать, что пени стимулирует своевременное исполнение налоговых обязательства, а также мотивирует налогоплательщика к повышению интенсивности погашения своих просроченных обязательств. Также, помимо пени существуют иные инструменты стимулирования своевременной уплаты налогов и сборов, однако все они являются карательными по отношению к налогоплательщику. На субъекты МСП данные меры карательного типа оказывают исключительно отрицательный эффект, с точки зрения развития. Субъект МСП, который не в состоянии своевременно погашать свои налоговые обязательства, вынужден нести дополнительные издержки, которые могут быть для него недопустимыми. Следовательно, для целей обеспечения развития МСП в России, необходимо сформировать инструмент, направленный на приращение возможностей погашения налоговых обязательств со стороны МСП. Суть инструмента должна быть сосредоточена на системе учета финансовой динамики субъекта МСП, а также единовременном хеджировании отрицательной динамики.

Предлагаемый инструмент может основываться на принципе опционного контракта. Опцион является деревативом, в основе которого находятся различные андерлаинги (базовые активы). В практике, на данный момент, в качестве андерлаинга могут быть задействованы различные активы: валюта, товары, индексы, процентные ценные бумаги, акции, а также реальные активы [2]. Продажа или покупка опционов в настоящее время реализуется как на бирже, так и на внебиржевом рынке. Ключевое различие заключается в том, что в случае биржевой сделки гарантом исполнения контракта выступает клиринговая палата биржи, а на внебиржевом рынке стороны контракта целиком принимают на себя все возможные риски, связанные с его исполнением. В рамках данного исследования речь идет о внебиржевом опционе, гарантом по которому должно выступать государство.

Уильям Ф.Шарп определяет опцион как заключенный между двумя лицами, в соответствии с которым одно лицо предоставляет право продать определенный актив по определенной цене в рамках определенного периода времени или предоставляет право продать определенный актив по определенной цене в рамках определенного периода времени [3]. Данная трактовка является одной из наиболее полноценных, выделяя базовые свойства опциона. Трактова Джона К.Халл коррелирует с данной трактовкой, утверждая, что опционы предоставляют их держателям право на осуществление определенных действий в будущем, однако держатель опциона не обязан реализовывать свое право [4]. В отечественной науке одну из наиболее распространенных трактовок опциону дал Селищев А.С., определив опцион, как срочный контракт, который дает право выбора одному из его участников (покупателю опциона): исполнить или отказаться от исполнения сделки по цене исполнения (страйк) - в определенную будущую дату - дату истечения срока - или до ее наступления [5]. Компиляция данных трактовок, позволяет сформулировать собственную, отражающую необходимые в рамках данного исследования свойства опциона: опцион - это срочный контракт, дающий право его держателю исполнить или отказаться от исполнения условий сделки по зафиксированной в момент заключения цене исполнения.

Прежде всего, опционный контракт дает возможность его покупателю зафиксировать свой риск изначально определенной суммой, которой он лишиться в случае неблагоприятного, для него, стечения обстоятельств. Однако при этом, потенциально возможная выгода по исполнения контракта ничем не ограничена. Следовательно, основная особенность опционного контракта состоит в том, что он дает его покупателю право выбора: исполнить контракт или отказаться от его исполнения.

Стоит отметить характеристика, определяющие опцион как финансовый инструмент. Опционный контракт характеризуется тремя ценами:

1. «Спот» цена.

2. Цена исполнения.

3. Опционная премия.

Текущая цена спот актива, лежащего в основе опционов колл и пут, отражает рыночную стоимость инвестиционных возможностей каждого конкретного актива. На сегодняшний день, котировки акций являются случайными величинами, а при их рассмотрении их во временной функции, они образуют дискретный случайный процесс. В реальности, котировки акций на бирже не могут быть зависимы исключительно от воли какого-либо конкретного инвестора, и они являются максимально объективным отражением экономических реалий. 
Цена исполнения опциона устанавливается биржей. Она устанавливается в зависимости от текущих котировок актива, который лежит в основе опционного контракта. Фиксация цены исполнения опционного контракта происходит в момент его заключения, и остается постоянной на протяжении всего периода существования контракта.

Опционная премия уплачивается покупателем продавцу опционного контракта. Она является выражением текущей рыночной цены опциона как финансового инструмента на момент заключения контракта. С целью обеспечения ликвидности вторичного опционного рынка, цены всех опционных контрактов регулярно котируются на бирже, тем самым обеспечивая возможность для всех заинтересованных инвесторов их купли-продажи.

Разность между спот ценой актива и ценой исполнения контракта является внутренней стоимостью опциона. Внутренняя стоимость опциона, для любого момента времени будет вносить вклад в формирование выигрыша или проигрыша участников опционного контракта в случае его немедленного исполнения.

Стоимость опционного контракта тесно связана со стоимостью его базисного актива. Данная связь наиболее очевидна непосредственно в момент истечения срока действия опционного контракта. С целью выявления данной связи необходимо пояснить понятия внутренней и временной стоимости опциона. Внутренняя стоимость опциона - это разница между ценой исполнения или ценой «страйк» и рыночной ценой актива. В случае если цена исполнения равна или больше рыночной цены актива, то внутренняя стоимость опциона будет равна нулю, т.е. чистый выигрыш не будет являться для покупателя опциона привлекательным. Временная стоимость опционного контракта способна существенно отличаться при одинаковых срокаx исполнения: по мере завершения опциона уменьшаться, в начальный момент времени может быть максимальной. Относительно покупателя опционного контракта, занимающего длинную позицию, каждый день действия опционного контракта уменьшает возможность реализации его с выгодой для себя. Однако относительно продавца ситуация снижения стоимости опциона является выгодной, так как он, реализовав его первоначально по одной цене, с приближением срока может довольно выгодно выкупить его. Прибылью продавца будет разница между ценой продажи и ценой покупки.

Необходимо отметить, что опционные контракты «put» и опционные контракты «call» не в состоянии быть меньше их внутренней стоимости. Однако они могут быть проданы по цене выше их внутренне стоимости, при наличии временной стоимости. Цена базисного актива, составляющего основу опциона, в случае роста, влечет относительное повышение риска, и, как следствие, повышение выплачиваемой продавцу премии. В свою очередь, снижение цены базисного актива оказывает влияние на снижение риска и на уменьшения размера премии, которая выплачивается продавцу. Именно поэтому для прогнозирования размера колебаний цены базисного актива и размера премии до недавнего времени использовалась экстраполяция («перенос» прошлых значений базисного актива и размеров премий на будущее с внесением некоторых поправками).

Сутью конструирования опционов является определение их теоретической цены. Существует множество методик определения теоретической цены опционов, однако основу составляют всего три базовые модели ценообразования опционов: Модель цен опционов Блэка-Шоулза и Биномиальная модель цен опционов. Прежде всего, имеет смысл описать принципы построения данных моделей.

Модель цен опционов Блэка-Шоулза. Данная модель, позволяет определить теоретическую цену на европейские опционные контракты, подразумевая, что в том случае, если базисный актив торгуется на рынке, то цена опциона на него косвенным образом уже установлена самим рынком.

Основным постулатом Модели Блэка-Шоулза является предположение о том, что элементом, определяющим стоимости опциона в первую очередь, является волатильность базисного актива. В зависимости от колебания базисного актива, цена на него возрастает или понижается, что оказывает прямопропорциональное влияние на стоимость опционного контракта. Следовательно, в том случае если, известна стоимость опционного контракта, то теоретически можно выявить наиболее вероятный уровень волатильности на рынке.

Модель Блэка-Шоулза создана для оценки справедливой стоимости опциона, используя историю акции. Данная модель может быть 
применена на «идеальном рынке» ценных бумаг. Следовательно, данная модель, в состоянии функционировать исключительно при следующих допущениях:

1. По базисному активу опциона дивиденды не выплачиваются в течение всего срока действия опциона.

2. Отсутствуют какие-либо транзакционные издержки и налоговые платежи, связанные с покупкой или продажей опционного контракта или базисного актива.

3. Краткосрочная безрисковая процентная ставка известна и является постоянной на протяжении всего срока действия опционного контракта.

4. Любой покупатель ценной бумаги имеет возможность получать ссуды по краткосрочной безрисковой ставке с целью оплаты любой части цены данной ценной бумаги.

5. Торговля базисным активом осуществляется непрерывно, а поведение цены базисного актива, в свою очередь, подчинено модели геометрического броуновского движения с известными параметрами. Следовательно, движение цены базисного актива является случайным во времени с дисперсией ставки, пропорциональной квадрату цены акции (логнормальное распределение цены акции).

Надо отметить, что в данной модели желание инвестора взять на себя риск оказывает косвенное влияние на стоимость опциона. Модель Блэка-Шоулза получила широкое распространение, даже не смотря на широкий перечень ограничений.

С учетом отсутствия транзакционных издержек и налогообложения стоимость опционного контракта «саll» может быть выявлена при помощи формулы, предложенной Блэком и Шоулзом. Данная формула применяется при попытках обнаружения ситуаций, при которых рыночная цена опционного контракта значительно отличается от его действительной цены. Опцион, продающийся по цене значительно ниже цены полученной при помощи формулы Блэка-Шоулза, является наиболее выгодным к покупке, и соответственно наоборот,- тот опцион, который торгуется по значительно более высокой цене, является кандидатом на продажу.

Модель Блэка-Шоулза достаточно сложна в использовании, так как в расчетах задействованы параметры, носящие оценочный характер. Основным параметром, носящим оценочный характер, являет волатильность. На данный момент, все торговые терминалы показывают уже рассчитанные цены, основанные на реальных данных. Расчет цен производится в динамике, относительно изменений на рынке.

Следует учесть, что модель Блэка-Шоулза существует при множестве теоретических допущений, некоторые из которых могут являться критическими. Самыми весомыми допущениями являются предположения об эффективности целевого рынка и случайном характере динамики рыночных цен. Следовательно, трейдеры вынуждены часто использовать вмененную волатильность, а не историческую. В рамках данного исследования, данное допущение также является значимым.

Биномиальная модель цен опционов. Изменения в сфере биржевой торговли создали предпосылки для появления новой модели и, как следствие, нового алгоритма расчета теоретической цены. Данный алгоритм получил название - Биномиальная модель цен опционов. Биномиальная модель цен опционов достаточно широко распространена. С математической точки зрения данная модель достаточно проста и очевидна благодаря уникальному методу расчета цены опционного контракта американского типа. Биномиальная модель цен опционов может быть построена исходя из допущений о движении рыночной цены базисного актива. Биномиальная модель, как правило, строится для европейских опционных контрактов, которые могут быть исполнены исключительно в день погашения. В том случае, если в качестве базисного актива используется обыкновенная акция, то следует предполагать, что по ней не выплачиваются дивиденды на протяжении всего срока действия опционного контракта.

Биноминальная модель рассматривается как распределение суммы случайных величин, каждая из которых принимает одно из двух значений: 1 с вероятностью р или 0 с вероятностью $q=(1-p)^{2}$. Данная модель задействует некий «гипотетический портфель без риска» для выявления цены опциона. «Гипотетический портфель без риска» приносит процентный доход. Биномиальная модель в чистом виде предполагает отсутствие иных изменений базиса, кроме различий в ценовой паре при торговле в дискретном режиме.

Кандидат технических наук, доцент кафедры менеджмента и административного управле- 
ния Красноярского Государственного Аграрного Университета Булгаков разработал уникальный метод оценки справедливой цены американского опционного контракта. Данный метод достаточно сложный с точки зрения математического аппарата. В данной работе этот метод упоминается лишь с целью продемонстрировать тот факт, что, несмотря на относительную простоту самой модели, на практике она может представлять собой достаточно сложный (математически) и громоздкий инструмент реально, торгующего на рынке, трейдера.

Главное теоретическое допущение классической Биномиальной модели состоит в том, что опционный рынок является эффективным. Данное предположение означает, что спекулянты не в состоянии получить сверхприбыль от комбинации с базисным инструментом и опционом при их одновременной покупке и/или продаже. Однако, биноминальная модель в свою очередь может учитывать факторы, которые модель Блэка-Шоулза не в состоянии рассмотреть.

Несмотря на то, что обе модели дают практически идентичные результаты, основным отличием биномиальной модели является то, что посредством ее проще учитывать возможность досрочного исполнения американского опциона. Данное свойство является очень важным при высокой безрисковой процентной ставке. И так как при традиционном экономическом анализе используется «дерево принятия решений», биномиальная модель является более наглядной и простой в применении. Основным ее недостатком является громоздкость расчетов и вычислений, однако она позволяет учесть практически все дополнительные факторы и варианты развития ситуации на рынке.

На основе выделенных свойств опционных контрактов предлагается ввести инструмент, базисным активом которого будет выступать прогнозируемый оборот субъекта МСП. Данный инструмент может быть назван - «Опцион на налоговые обязательства субъекта МСП» Сущность опциона может быть интерпретирована в условном алгоритме его реализации (рис.1).

Таким образом, государственные органы (вероятнее всего налоговая инспекция) прогнозируют налогооблагаемую базу субъекта МСП на предстоящий период (финансовый год, квартал или месяц), посредствам разработанной в предыдущей главе модели. На данную величину выпускается опцион, которые предлагается государственными органами анализируемому субъекту МСП. Субъект МСП в праве отказаться от приобретения заключения опционного контракта. В том случае если субъект МСП заключает данный опционный контракт, то по истечению его срока предприятие получает возможность его реализовать. В том случае, если налогооблагаемая база предприятия превысила прогнозируемое значение, то оно в праве либо реализовать опцион, погасив все свои налоговые обязательства полностью, либо отказаться от исполнения опциона уплатив штраф в размере установленной процентной ставки от суммы превышения, и налог в соответствии с определённой прогнозом налоговой базы. В случае, если налогооблагаемая база предприятия равна прогнозируемому значению, оно в праве реализовать опцион, погасив все свои налоговые обязательства в соответствии с прогнозируемой/ фактической налоговой базой. А если налогооблагаемая база предприятия ниже прогнозируемого значения, оно в праве реализовать опцион, погасив все свои налоговые обязательства в соответствии с фактической налоговой базой и получить от государства бонус, равный установленной процентной ставки от суммы недостачи.

Таким образом, государство получает в руки два ключевых варьируемых инструмента управления развитием сектора МСП, посредствам данного опциона:

1. Прогнозируемый размер налогооблагаемой базы. Использую разработанную модель государство получает возможность прогнозировать реакцию МСП на институциональные трансформации, тем самым повышая или понижая параметр прогнозируемой налогооблагаемой базы. При этом данный параметр имеет исключительно расчетный характер, и не содержит экспертной, что значительно повышает его объективность.

2. Процентная ставка контракта. Данный параметр определяет либо потенциальный денежный доход предприятия, либо дополнительный доход государства. Варьируя данный параметр, государство в состоянии повышать уровень поддержки МСП, либо (в условиях неуклонно экономического роста) насыщать бюджеты различных уровней дополнительными средствами.

Предприятие в состоянии применять модели Блэка-Шоулза, или Биномиальную модель для определения будущей цены данного опциона, 
1. Государственные органы применяют модель оценки проталлакса элементов микроинституциональной среды субъекта МСП в зависимости от трансформации влияния элементов макроинституциональной среды МСП, с целью прогнозирования налогооблагаемой базы субъекта МСП в предстоящем периоде

2. Предприятие заключает данный опционный контракт с государственными органами

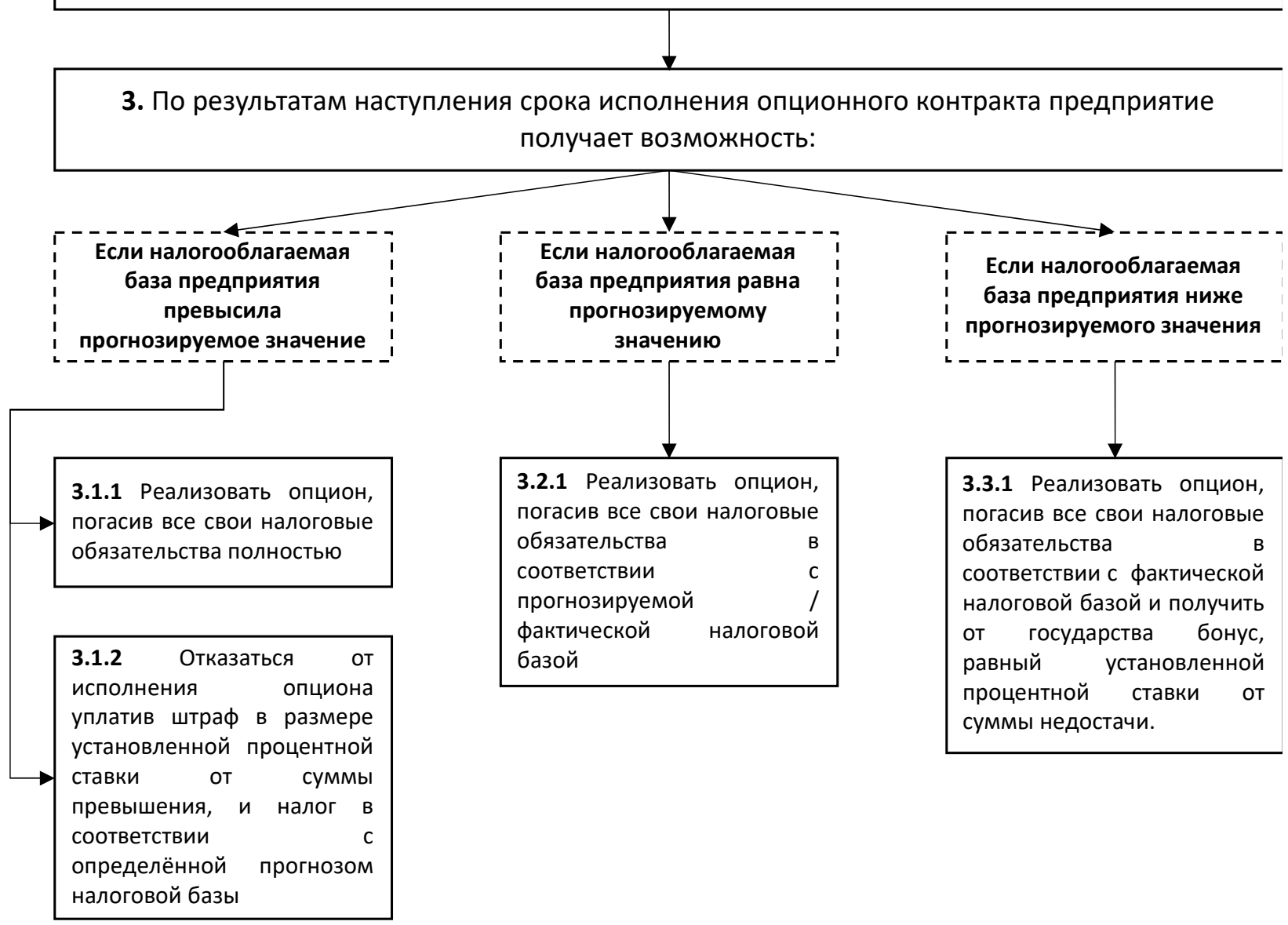

Puc. 1. Алгоритм реализации опциона на налоговые обязательства субъекта МСП

что в свою очередь позволить контролировать спрос на данные опционные контракты со стороны МСП. Данный инструмент в значительной мере позволяет компенсировать отрицательное влияния на субъекты МСП со стороны институциональной среды. При этом, внедрение данно- го инструмента, также как и его реализация не требует корректировки макроэкономической политики в отношении крупного бизнеса, что в полной мере отвечает условиям обеспечения развития МСП в контексте целевой поддержки именно крупного бизнеса.

\section{Библиографический список}

1. Фактограф. Велико ли налоговое бремя в России? // URL: https://www.factograph.info/a/28722436.html (дата обращения: 15.08.2020)

2. Финансовые инвестиции образовательный центр. Опцион // URL: https://allfi.biz/glossary/eng/O/option.php (дата ображения: 15.08.2020)

3. Уильям Ф. Шарп, Гордон Дж. Александер, Джеффри В. Бейли Инвестиции - М. ИНФРА-М, 2013-635 с. 
4. Джон К. Халл Опционы, фьючерсы и другие производные финансовые инструменты - М., 2012-269 с.

5. Селищев А.С., Маховикова Г. А. Рынок ценных бумаг - М., Юрайт, 2012-128 с.

6. Конников Е.А., Селищев А. С. Опцион на налоговые обязательства // Финансы и бизнес. 2014. № 2. С. 53-6

7. Конников Е. А. Сравнительный анализ эффективности использования модели цен опционов Блэка-Шоулза и биномиальной модели цен опционов // Современные аспекты экономики. 2013. № 10 (194). С. 27-37.

8. Конников E. А. Методы определения теоретической цены опционов // Эффективность использования модели Блэка-Шоулза, Биномиальной и Монте-Карло для определения теоретической цены опционов / Саарбрюккен, 2014. 